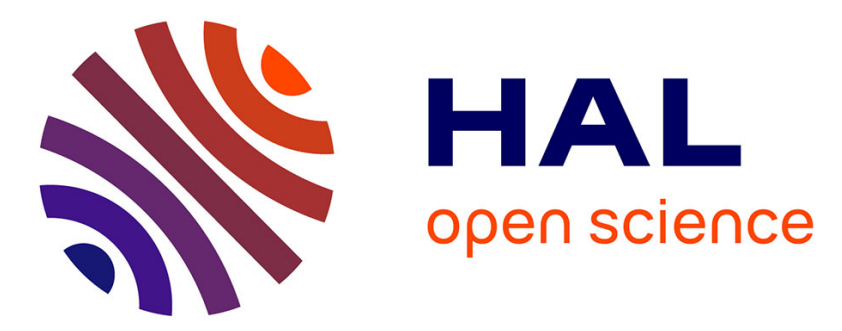

\title{
Subclasses of monoclonal (type I) immunoglobulin G cryoglobulins : 2 report on two distinct cases with myeloma 34
}

Tania Petersen, Sébastien Rivière, Stéphanie Malbos, Yannick Chantran, Aïcha Abbas, François Chasset, Arsene Mekinian, Jérémie Sellam, Laurent Garderet, Pierre Aucouturier

\section{To cite this version:}

Tania Petersen, Sébastien Rivière, Stéphanie Malbos, Yannick Chantran, Aïcha Abbas, et al.. Subclasses of monoclonal (type I) immunoglobulin G cryoglobulins: 2 report on two distinct cases with myeloma 3 4. Clinical Laboratory, 2018, 64 (4), pp.615-618. 10.7754/Clin.Lab.2017.171043 . inserm01826683

\section{HAL Id: inserm-01826683 https://www.hal.inserm.fr/inserm-01826683}

Submitted on 29 Jun 2018

HAL is a multi-disciplinary open access archive for the deposit and dissemination of scientific research documents, whether they are published or not. The documents may come from teaching and research institutions in France or abroad, or from public or private research centers.
L'archive ouverte pluridisciplinaire HAL, est destinée au dépôt et à la diffusion de documents scientifiques de niveau recherche, publiés ou non, émanant des établissements d'enseignement et de recherche français ou étrangers, des laboratoires publics ou privés. 
Case report

\section{Subclasses of monoclonal (type I) immunoglobulin G cryoglobulins : report on two distinct cases with myeloma}

Tania Petersen ${ }^{1,2}$, Sébastien Rivière ${ }^{3}$, Stéphanie Malbos ${ }^{4}$, Yannick Chantran ${ }^{1,2}$, Aïcha Abbas $^{2}$, François Chasset ${ }^{5}$, Arsène Mékinian ${ }^{3}$, Jérémie Sellam ${ }^{1,4}$, Laurent Garderet ${ }^{1,6}$, Pierre Aucouturier ${ }^{1,2}$

${ }^{1}$ Sorbonne Universités, UPMC Univ Paris 06, Inserm UMRS 938, Hôpital St-Antoine, F-75012, Paris, France.

2 Département d'Immunologie Biologique, AP-HP, Hôpital St-Antoine, F-75012 Paris, France.

${ }^{3}$ Service de Médecine Interne, AP-HP, Hôpital St-Antoine, F-75012 Paris, France.

${ }^{4}$ Service de Rhumatologie, AP-HP, Hôpital St-Antoine, F-75012 Paris, France.

${ }^{5}$ Service de Dermatologie, AP-HP, Hôpital Tenon, F-75020 Paris, France.

${ }^{6}$ Service d'Hématologie Clinique, AP-HP, Hôpital St-Antoine, F-75012 Paris, France. Corresponding author:

Pierre Aucouturier, Inserm UMRS 938, Hôpital St-Antoine, F-75012, Paris, France.

Phone : + 33-149281678

Fax : + 33-149282206

E-mail : pierre.aucouturier@inserm.fr

Reprints will not be available from the author

Sources of funding : this work was supported by Assistance Publique - Hôpitaux de Paris (AP-HP) and by Institut National de la Santé et de la Recherche Médicale (Inserm).

Declaration of interest : The authors declare that they have no conflicts of interest regarding this study.

Running title : IgG subclasses of monoclonal cryoglobulins 


\section{SUMMARY}

Background : While different clinical manifestations of IgM and IgG monoclonal cryoglobulins have been demonstrated, little is known on the roles of IgG subclasses in the pathophysiology of these conditions.

Methods : In two cases of myeloma-associated monoclonal (type I) cryoglobulinemia with quite distinct clinical and biological features, serum samples were analyzed using an original IgG subclass-specific immunoblotting technique.

Results : The first case had painful arthritis of hands and feet, with skin purpura and a sharp decrease of complement $\mathrm{C} 4$ level, and the cryoglobulin was of IgG1 subclass. The second case displayed mostly thrombotic lesions of the limb extremities, C3 and C4 serum levels were normal, and the cryoglobulin belonged to the IgG2 subclass.

Conclusion : Type I cryoglobulins of distinct IgG subclasses may result in different syndromes. In both cases, the treatment relies on eradication of the underlying plasma cell dyscrasia.

\section{KEY WORDS}

Cryoglobulin - Monoclonal immunoglobulin - IgG subclasses 


\section{INTRODUCTION}

Cryoglobulins are circulating complexes of immunoglobulins (Ig) that become insoluble at low temperature. According to Brouet et al [1], the content of cryoprecipitates defines three types based on the presence of polyclonal and/or monoclonal Ig. Type I cryoglobulins are made up of a pure monoclonal Ig that binds to itself through variable domains [2].

Clinical events relating to monoclonal cryoglobulinemia are quite inconstant in both form and severity: while asymptomatic cases are not uncommon, others may present with cutaneous purpuric lesions or ischemic necrosis, Raynaud phenomenon, arthritis, neurological disorders and renal complications $[3,4]$.

Clinical manifestations likely relate to intrinsic properties of the cryoglobulins, including effector functions of involved monoclonal Ig. While patients with monoclonal IgM and IgG cryoglobulins seem to have distinct pathological patterns [4,5], only few data are currently available on the influence of IgG subclasses.

We report on two myeloma cases with quite distinct presentations and outcome that might relate to different monoclonal cryoglobulin IgG subclasses. IgG subclass typing was performed using a homemade immunoblotting method [6]. Briefly, serum samples were submitted to thin-layer agarose gel zone electrophoresis, transferred by single pressure onto a nitrocellulose membrane, incubated with monoclonal antibodies specific for kappa, lambda, IgG, IgG1, IgG2, IgG3 and IgG4 isotypes (clones HP6053, HP6054, HP6018, NL16, GOM2, ZG4 and RJ4, respectively), followed by alkaline phosphataseconjugated anti-mouse IgG antiserum, and then revealed with tetrazolium nitroblue / bromo-chloro-indolylphosphate.

\section{CASE PRESENTATION}

\section{Case 1 :}

A 64 year-old woman with a smoldering myeloma diagnosed since two years presented with painful bilateral hand and foot arthritis combined with purpuric skin lesions of the feet (Figure 1, upper panel). She presented with anemia (Hb $8.2 \mathrm{~g} / \mathrm{dL}$ ) and had normal serum creatinine and calcium levels. The monoclonal IgG kappa spike had recently increased to $30.7 \mathrm{~g} / \mathrm{L}$, with concomitantly decreased serum IgA and IgM levels $(0,32$ 
$\mathrm{g} / \mathrm{L}$ and $0,16 \mathrm{~g} / \mathrm{L}$, respectively). A serum cryoglobulin was then detected, and immunofixation and immunoblotting analyses of the purified cryoprecipitate demonstrated a pure monoclonal IgG of IgG1 subclass (Figure 2, upper panel).

Additional biological data showed an increased serum C-reactive protein $(35.1 \mathrm{mg} / \mathrm{L})$, a normal serum complement C3 level (1.09 g/L) and a very low complement C4 level $(0.03 \mathrm{~g} / \mathrm{L})$. Serological results for HIV, HBV and HCV were negative. Proteinuria was significant ( $1.25 \mathrm{~g} /$ day) and included a predominant kappa-type monoclonal $\mathrm{Ig}$ free light chain (Bence-Jones proteinuria).

Imaging studies revealed osteolytic lesions of the skull. Bone marrow aspiration showed $32 \%$ dystrophic plasma cells.

A skin biopsy of a foot lesion revealed leukocytoclastic vascular lesions with microthrombi. Cutaneous and articular vasculitis was diagnosed.

An induction regimen combining Bortezomib, Cyclophosphamide and Dexamethasone (VCD) was initiated. A partial hematological remission was achieved upon four cycles. Autologous peripheral blood stem cells were then collected, and a myeloablative chemotherapy with Melphalan $200 \mathrm{mg} / \mathrm{m}^{2}$ was given followed by autologous stem cell transplantation. Three months later, she received two cycles of Bortezomib, Thalidomide and Dexamethasone (VTD) as a consolidation process. No maintenance treatment was given.

Both polyarthritis and skin purpura disappeared after the first successful cycle of VCD. Currently, the patient is in a good general condition, with a partial remission three and a half years after the autologous peripheral blood stem cell transplantation. The serum monoclonal IgG level is stable at $2.8 \mathrm{~g} / \mathrm{L}$, and the serum cryoglobulin is currently undetectable. Serum complement fractions returned to normal levels.

\section{Case 2 :}

A 89 year-old woman presented with purpuric skin lesions and edema of the extremities.

Since 2 months she had complained about asthenia, arthralgia of metacarpal, interphalangeal, metatarsal joints and wrists. Clinical examination revealed necrotic 
purpuric lesions localized on the hands, legs and feet (Figure 1, lower panel). No synovitis was found.

Laboratory data showed a moderate anemia (Hb $11 \mathrm{~g} / \mathrm{dL})$, normal creatinine and calcium serum levels and no significant proteinuria or hematuria. Serum protein electrophoresis and immunofixation demonstrated a monoclonal IgG of kappa type that was assessed at $14 \mathrm{~g} / \mathrm{L}$. Serum polyclonal immunoglobulin levels were normal (IgA $1,92 \mathrm{~g} / \mathrm{L}, \operatorname{IgM} 0,57 \mathrm{~g} / \mathrm{L})$. An abundant serum cryoglobulin was detected, and immunofixation and immunoblotting analyses of the purified cryoprecipitate demonstrated a pure monoclonal IgG of IgG2 subclass (Figure 2, lower panel).

No bone lesions were detected on MRI and X-ray analyses. Bone marrow aspiration showed $18 \%$ dystrophic plasma cells, with a normal karyotype. There was no evidence of complement activation, as suggested by normal serum levels of $\mathrm{C} 3$ and $\mathrm{C} 4$ fractions (0,96 g/L and 0,22 g/L, respectively). Serological results for HIV, HBV and HCV were negative. The skin biopsy showed multiple thromboses of the superficial dermis capillaries, without vasculitis or inflammatory infiltrates.

Stage I myeloma with complicating cryoglobulinemia skin lesions was diagnosed and a treatment with Bortezomib and Dexamethasone was initiated. Despite this treatment, arthralgia worsened and extensive ischemic and necrotic lesions appeared on the legs (figure 1, lower panel). After a severe sepsis of urinary origin, the patient died from hemorrhagic shock related to a duodenal ulcer.

\section{DISCUSSION}

These two myeloma patients with monoclonal IgG cryoglobulins had quite distinct presentations, with predominant joint inflammatory disease in the first one versus important skin ischemic lesions in the other. In case 1, inflammation may relate at least in part to the IgG1 isotype of the cryoglobulin; indeed, this subclass is known to display pro-inflammatory effector properties, namely activation of the complement classical pathway complement and binding to Fc receptors on mononuclear cells. In case 2, normal serum complement $\mathrm{C} 3$ and $\mathrm{C} 4$ may be explained by the $\mathrm{IgG} 2$ isotype of the cryoglobulin. Indeed, this IgG subclass poorly activates the complement classical pathway and has little or no affinity to Fc receptors on effector cells. 
Previous studies of IgG subclasses in type I cryoglobulins demonstrated an overrepresentation of $\operatorname{IgG} 2$ and $\operatorname{IgG} 3$ as compared with MGUS and myeloma, although IgG1 remained the most frequent $[1,7,8]$. However, these reports included no indication on the clinical and biological patterns corresponding to each IgG subclass cryoglobulin, and thus their pathological significance remains quite obscure.

To our knowledge, the only article with identified subclass of monoclonal cryoglobulins in clinically and pathologically documented patients is that from Karras et al [9] who described 2 cases with membranoproliferative glomerulonephritis due to monoclonal IgG3 kappa cryoglobulins. In both cases, kidney sub-endothelial deposits included both monotypic IgG3 kappa and complement fraction C3; distal purpuric lesions of the skin were found in one of them, with vascular deposition of IgG3 kappa and C3, and there was no evidence of cryoglobulin-related extra-renal involvement in the other reported case. This observation suggests a proneness of this IgG subclass to accumulate in the glomerulus, as also found in other monoclonal Ig deposition diseases [10].

Currently available data on IgG1 and IgG2 monoclonal cryoglobulins provide no clinical and pathological data that would tentatively explain their respective pathogenic roles. None of the present cases had objective renal involvement.

Different clinical patterns have been demonstrated in IgG and IgM monoclonal cryoglobulins, the most remarkable of which are more frequent kidney involvement and skin lesions with necrosis in IgG cryoglobulins [4]. Contrary to mixed (type II) cryoglobulinemia that mostly feature leukocytoclasic vasculitis, cutaneous lesions relating to pure monoclonal cryoglobulins are most often due to thrombotic purpura with necrosis [11-13].

In our first case, the successful treatment of myeloma allowed curing arthralgia manifestations right away. On the contrary, the second patient did not respond to the initial hematological treatment and died of hemorrhagic and septic complications.

\section{CONCLUSION}

Considering the diversity of clinical expression in monoclonal IgG cryoglobulinemia, systematic identification of involved IgG subclasses could help precising the pathophysiology. The two cases reported here illustrate this point. In addition, 
successfully treating the underlying monoclonal plasma cell dyscrasia appears to be paramount to a successful outcome. 


\section{REFERENCES}

1. Brouet JC, Clauvel JP, Danon F, Klein M, Seligmann M. Biologic and clinical significance of cryoglobulins. A report of 86 cases. Am J Med 1974;57(5):775788 (PMID : 4216269).

2. Gerber-Jenson B, Kazin A, Kehoe JM, Scheffel C, Erickson BW, Litman GW. Molecular basis for the temperature-dependent insolubility of cryoglobulins. X. The amino acid sequence of the heavy chain variable region of McE. J Immunol 1981;126(3):1212-1216 (PMID : 6780622).

3. Terrier B, Karras A, Kahn JE, et al. The spectrum of type I cryoglobulinemia vasculitis: new insights based on 64 cases. Medicine (Baltimore) 2013;92(2):6168 (PMID : 23429354).

4. Harel S, Mohr M, Jahn I, et al. Clinico-biological characteristics and treatment of type I monoclonal cryoglobulinaemia: a study of 64 cases. Br J Haematol 2015;168(5):671-678 (PMID : 25363150).

5. Néel A, Perrin F, Decaux O, et al. Long-term outcome of monoclonal (type 1) cryoglobulinemia. Am J Hematol 2014;89(2):156-161 (PMID : 24532335).

6. Briault S, Courtois-Capella M, Duarte F, Aucouturier P, Preud'Homme JL. Isotypy of serum monoclonal immunoglobulins in human immunodeficiency virus-infected adults. Clin Exp Immunol 1988;74(2):182-184 (PMID : $3147151)$.

7. Virella G, Hobbs JR. Heavy chain typing in IgG monoclonal gammopathies with special reference to cases of serum hyperviscosity and cryoglobulinaemia. Clin Exp Immunol 1971;8(6):973-980 (PMID : 4997073).

8. Abraham GN, Podell DN, Wistar R Jr, Johnston SL, Welch EH. Immunological and structural properties of human monoclonal IgG cryoglobulins. Clin Exp Immunol 1979;36(1):63-70 (PMID : 111883).

9. Karras A, Noël LH, Droz D, Delansorne D, et al. Renal involvement in monoclonal (type I) cryoglobulinemia: two cases associated with IgG3 kappa cryoglobulin. Am J Kidney Dis 2002;40(5):1091-1096 (PMID : 12407656).

10. Nasr SH, Markowitz GS, Stokes MB, et al. Proliferative glomerulonephritis with monoclonal IgG deposits: a distinct entity mimicking immune-complex glomerulonephritis. Kidney Int 2004;65(1):85-96 (PMID : 14675039). 
11. Ninomiya S, Fukuno K, Kanemura N, et al. IgG type multiple myeloma and concurrent IgA type monoclonal gammopathy of undetermined significance complicated by necrotizing skin ulcers due to type I cryoglobulinemia. J Clin Exp Hematopathol 2010;50(1):71-74 (PMID : 20505279).

12. Kluger N, Sirvente J, Rigau V, Guillot B. Extensive thrombotic purpura revealing multiple myeloma associated - type I cryoglobulinemia. Br J Haematol. 2011;154(1):1 (PMID : 21496001).

13. Payet J, Livartowski J, Kavian N, et al. Type I cryoglobulinemia in multiple myeloma, a rare entity: analysis of clinical and biological characteristics of seven cases and review of the literature. Leuk Lymphoma. 2013;54(4):767-777 (PMID : 22385269). 


\section{LEGENDS TO FIGURES}

Figure 1. Clinical symptoms : metacarpal, interphalangeal and metatarsal arthritis and limited skin purpura of a foot in patient 1 (upper panel); hand and foot purpuric skin lesions in patient 2 (lower panel, left) and severe ischemic and necrotic evolution (lower panel, right).

Figure 2. Immunochemical studies of serum and purified cryoglobulins :

Serum immunofixation (a, d) and immunoblotting (b, e) ; immunofixation on purified cryoglobulin (c, f). 
Figure 1:

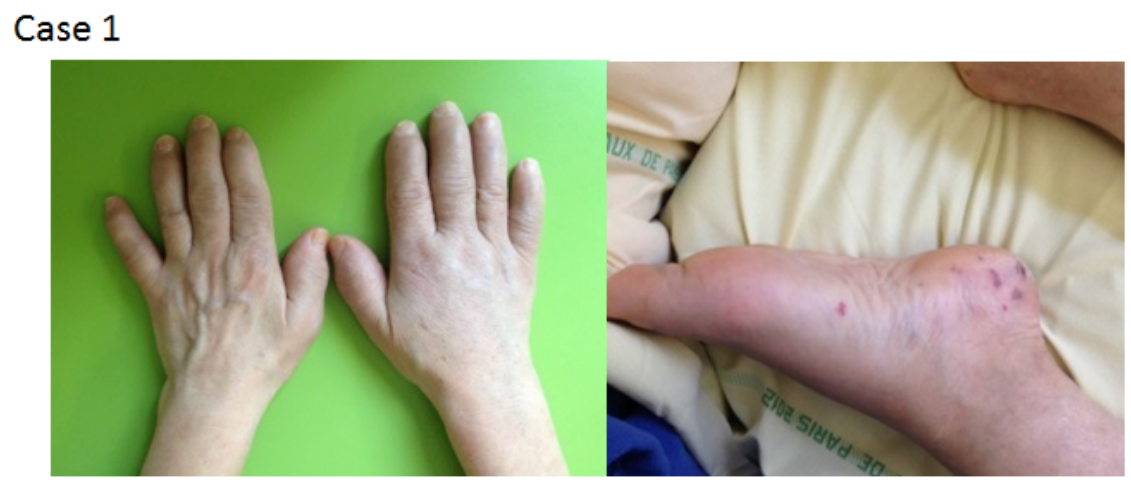

Case 2

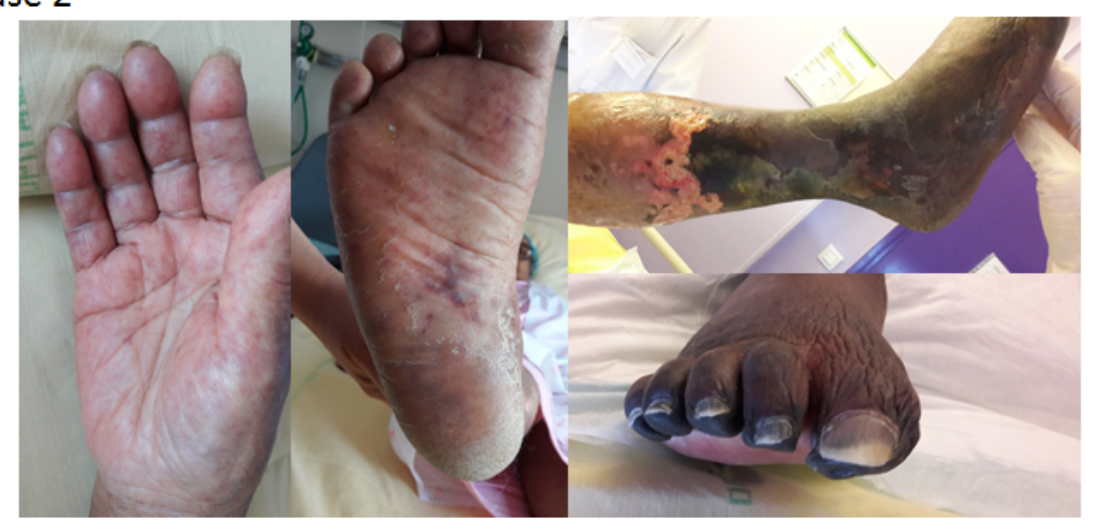

Figure 2:

Case 1

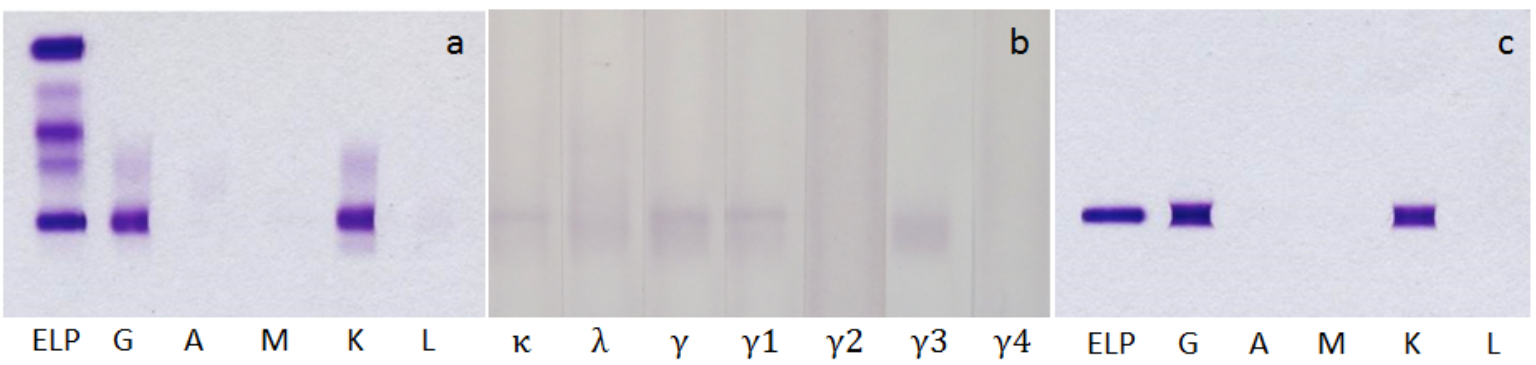

Case 2

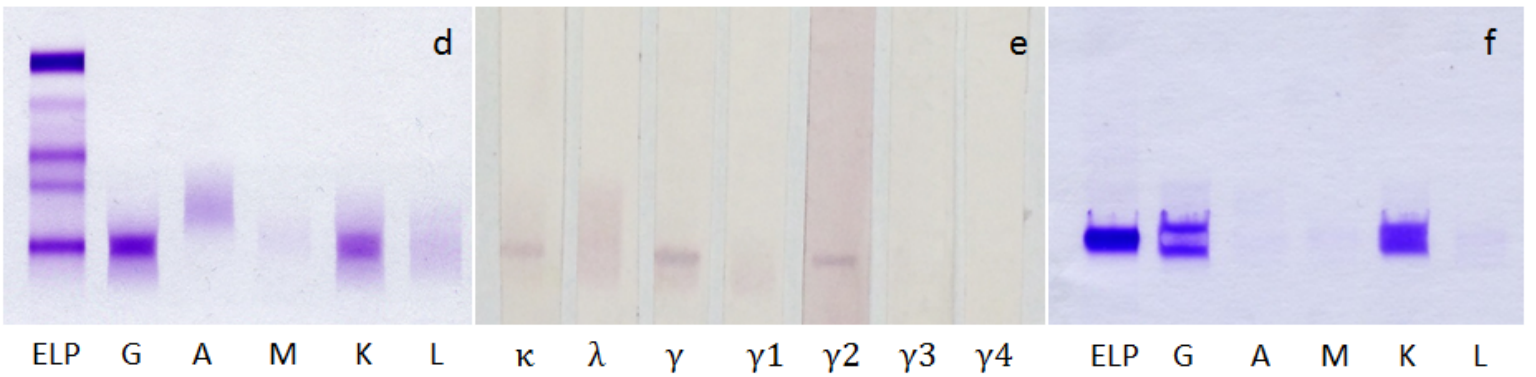

